\title{
Effects of acidophilic protozoa on populations of metal-mobilizing bacteria during the leaching of pyritic coal
}

\author{
D. BARRIE JOHNSON* and LOUISE RANG $\dagger$
}

School of Biological Sciences, University of Wales, Bangor, Gwynedd LL57 2UW, UK

(Received 17 December 1992; revised 1 March 1993; accepted 4 March 1993)

\begin{abstract}
Five acidophilic protozoa (three flagellates, one ciliate and one amoeba) were isolated from acid mine water and a coal biotreatment plant, and grown in mixed cultures with acidophilic bacteria. Cultures were routinely maintained in ferrous sulphate media: in media containing pyrite or pyritic coal, protozoa grew in cultures containing coarse-grain $(61-200 \mu \mathrm{m})$ but not fine-grain $(<61 \mu \mathrm{m})$ minerals. In cultures of pyritic coal, protozoa grazed iron-oxidizing and heterotrophic bacteria, but to varying extents. One of the flagellates appeared only transiently in coal leachates, whilst the four others persisted through the $100 \mathrm{~d}$ incubation. A reduction of numbers of unattached iron-oxidizing acidophiles, due to protozoan grazing, did not always result in lower rates of pyrite oxidation. The presence of protozoa was noted to effect changes in acidophilic populations, in particular often causing Leptospirillum ferrooxidans to become the dominant iron-oxidizer at an earlier stage than in corresponding protozoa-free controls.
\end{abstract}

\section{Introduction}

The use of acidophilic, metal-mobilizing bacteria in the bioprocessing of ores is an established area of biotechnology. Applications include leaching of low-grade ores of copper and uranium, beneficiation of refractory gold ores, and removal of pyritic sulphur from coal (Norris, 1990; Bos et al. 1992). The principal bacteria involved in pyrite oxidation in mesophilic environments are the ironoxidizing chemolithotrophs Thiobacillus ferrooxidans and Leptospirillum ferrooxidans, though in higher temperature environments a different metal-mobilizing microflora exists (Norris \& Ingledew, 1992). It is known that, although bioleaching environments and acid mine drainage waters are often described as extreme in terms of their $\mathrm{pH}$ and concentrations of metal ions, microorganisms other than acidophilic iron-oxidizers are active within them. These are primarily bacteria, and include other chemolithotrophs, mixotrophs and heterotrophic acidophiles (Harrison, 1984; Johnson, 1991 a). Eukaryotic life in acidic mine spoil effluents and leaching liquors appears to be restricted largely to some yeasts

*Author for correspondence. Tel. (0248) 382358; fax (0248) 370731; e-mailBSS041@UK.AC.BANGOR.

$\dagger$ Present address: School of Medicine, University of London, London, Ontario, Canada. and moulds, and protozoa. Early reports by Lackey (1938) and Joseph (1953) of protozoa (Euglena spp., Amoeba proteus and Paramecium caudatus) in acid mine drainage were later substantiated by Ehrlich (1963) and Johnson (1991a). Ehrlich (1963), working with acid water ( $\mathrm{pH} 2.5$ ) from a copper mine (copper, $0.8 \mathrm{~g}^{-1}$, and total iron, $1.06 \mathrm{~g} \mathrm{l}^{-1}$ ) did not find protozoa in fresh water samples, but noted that unidentified amoebae were present in stored ( $49 \mathrm{~d}$ ) samples at about 350 organisms $(\mathrm{ml} \text { mine water) })^{-1}$. A biflagellate protozoan (but no amoebae) also grew in enrichment cultures of the mine water. Both protozoa were considered to be feeding on the acidophilic bacteria present in the cultures. A biflagellate protozoan similar to that described by Ehrlich (1963) and tentatively identified as a Eutreptia spp. was isolated from 'acid streamer' bacterial growths by McGinness \& Johnson (1992). The organism was shown to be obligately acidophilic ( $\mathrm{pH}$ range $1.8-4.5$ ), tolerant of ferrous (to $50 \mathrm{mM}$ ) and ferric (to $25 \mathrm{mM}$ ) iron, but highly sensitive to other metals such as copper and silver. The protozoan was shown to be capable of grazing a wide range of acidophilic bacteria, and appeared to graze $T$. ferrooxidans in preference to $L$. ferrooxidans. However, attempts to grow the protozoan in media containing pyrite were unsuccessful, even though bacteria were numerous and physicochemical conditions were conducive to growth of the flagellate.

This paper describes the effects of five acidophilic 
protozoan isolates on bacterial numbers and rates of pyrite dissolution in cultures of pyritic coal inoculated with mixed populations of acidophilic bacteria.

\section{Methods}

Isolation of protozoa. Five protozoan isolates were used in these experiments. One of these (PR1) was that described by McGinness \& Johnson (1992) which had been isolated from Cae Coch sulphur mine, North Wales. Isolate PR2 was obtained from an experimental coal leaching reactor at the Idaho National Engineering Laboratory (INEL), USA; the appearance of this flagellate (which superficially resembled PR1) had been found to coincide with a severe decline in bacterial numbers in the leaching liquor (Graham Andrews, INEL, personal communication). Enrichment cultures for PR2 were prepared in $20 \mathrm{~mm}$-ferrous sulphate medium, $\mathrm{pH} 2.0$, using samples of coal leachate, incubated at $30^{\circ} \mathrm{C}$. The other three protozoa (PR3, PR4 and PR5) were isolated, as PR1, from Cae Coch mine. As described elsewhere (Johnson et al., 1979), the main microbiological features within this mine (a pyrite ore body that has been undisturbed for over 50 years) are the extensive growths $\left(>100 \mathrm{~m}^{3}\right)$ of 'acid streamers' in its main drainage stream and on moist rock faces. In some areas, acid streamers, comprising a mixed population of acidophilic bacteria, contain protozoa which may be observed actively grazing the streamer bacteria. In some microsites, there are mixed protozoan populations, whilst in others, a single protozoan morphology appears to dominate. Small fragments of streamers were teased out using sterile forceps, inoculated into $20 \mathrm{~mm}$-ferrous sulphate medium and incubated at $30^{\circ} \mathrm{C}$. Following iron oxidation, the cultures were examined regularly using a phase contrast microscope for the presence of protozoa. Three cultures, each containing a single protozoan morphological type (a ciliate PR3, a flagellate PR4, and an amoeba PR5) were obtained in this way. Cultures were maintained by regular (every $14 \mathrm{~d}$ ) subculturing in ferrous sulphate medium and checked regularly for 'purity' of protozoa. Control cultures containing the same mixed bacterial population but without protozoa were prepared by filtering ferrous iron cultures towards the end of the oxidation phase (i.e. before protozoan populations had increased significantly) through $3 \mu \mathrm{m}$ membrane filters (Millipore). These cultures were regularly inspected for the presence of protozoa, and were maintained in ferrous sulphate medium.

Effect of particle size of pyrite and pyritic coal on protozoan activity. In an attempt to ascertain whether the lack of growth of flagellate PR1 in pyrite cultures reported by McGinness \& Johnson (1992) was related to the particle size of the mineral used, ground pyrite from Cae Coch mine $\left(80 \%, w / w, \mathrm{FeS}_{2}\right)$ was graded via wet sieving into two fractions: $61-200 \mu \mathrm{m}$ and $<61 \mu \mathrm{m}$. Cultures $(50 \mathrm{ml}$ in $100 \mathrm{ml}$ conical flasks) containing $1 \mathrm{~g}$ of pyrite of either size range were inoculated with the five protozoa (PR1-PR5) from ferrous sulphate cultures and incubated unshaken (daily agitation) at $30^{\circ} \mathrm{C}$. Counts of protozoa in these cultures were made at regular intervals, as described below. A similar set of cultures was established using pyritic coal, graded within the same particle size range.

Effect of protozoa on bacterial leaching of pyritic coal. Replicate cultures ( $100 \mathrm{ml}$ medium in $250 \mathrm{ml}$ conical flasks) containing $2 \mathrm{~g}$ pyritic coal were inoculated $(5 \%, \mathrm{v} / \mathrm{v})$ with cultures containing active populations of the five acidophilic protozoan isolates, and also with corresponding protozoa-free mixed cultures. These were incubated at $30^{\circ} \mathrm{C}$ unshaken (daily agitation) for $100 \mathrm{~d}$, and were analysed at regular intervals for soluble iron (by atomic absorption spectrophotometry) and numbers of protozoa, and of iron-oxidizing and heterotrophic bacteria. The coal used in these experiments contained
$20 \% \mathrm{FeS}_{2}$ (Johnson, 1991 b) and was within the particle size range 61-200 $\mu \mathrm{m}$.

Microbiological techniques. Counts of protozoa were made on culture suspensions using phase contrast microscopy, as described elsewhere (McGinness \& Johnson, 1992). Numbers of acidophilic bacteria in the solution phase (i.e. unattached cells) were assessed using plate counts of culture diluents. The solid media used were the overlaid ferrous iron medium described by Johnson \& McGinness (1991) for iron-oxidizers and acidified yeast extract medium (Walton \& Johnson, 1992) for heterotrophs. Speciation of iron-oxidizers into $T$. ferrooxidans and $L$. ferrooxidans was made on the basis of colony morphologies (using a low power binocular microscope at magnification range 10 to $50 \times$; Johnson \& McGinness, 1991) and confirmed by phase contrast microscopy (magnification $250 \times$ ).

\section{Results}

Mixed microbial cultures containing individual protozoan species were successfully established in ferrous sulphate media. Protozoan growth in cultures that had been inoculated with streamers from Cae Coch mine was highly variable. In some, no protozoa were observed, in some others there was more than one morphological type, whilst in others there appeared to be single morphological types. Those in the latter category were repeatedly subcultured to produce cultures that were considered 'pure' in terms of protozoan species. No attempt at regulating bacterial populations in these cultures was made. Besides containing iron-oxidizing acidophiles, they also contained heterotrophic bacteria and, occasionally, moulds. The elimination of protozoa from cultures by filtering through $3 \mu \mathrm{m}$ membranes was successful in about $90 \%$ of cases; occasionally some smaller flagellates passed through the membrane, but these could be removed successfully by repeated filtration. Membrane filtration did not affect the composition of the bacterial community in these cultures, as evidenced by diversity of colony morphologies on solid media.

Of the five protozoa that were established in liquid media, three were flagellates, one a ciliate and one an amoeba. The three flagellates, identified as PR1, PR2 and PR4, had similar morphologies: biflagellated (apparently attaching to solid substrata with one flagellum and using the other for food capture), elongated when active, but becoming almost coccoid during inactive phases; all were identified as belonging to the genus Eutreptia, or possibly Bodo (Patterson \& Hedley, 1992). Isolate PR4 was somewhat larger $(10 \mu \mathrm{m}$ in length) than the other two flagellates (PR1 $8 \mu \mathrm{m}$, PR2 $7 \mu \mathrm{m}$; all were about $1 \mu \mathrm{m}$ in diameter). Isolate PR3 was a small ciliate $(12 \times 7 \mu \mathrm{m})$ with a flattened, rounded morphology and with several long trailing cilia on its lower surface. It was tentatively identified as a member of the genus Cinetochilum (Patterson \& Hedley, 1992). Isolate PR5 was a small $(5-10 \mu \mathrm{m})$ cylindrical limax amoeba, producing 


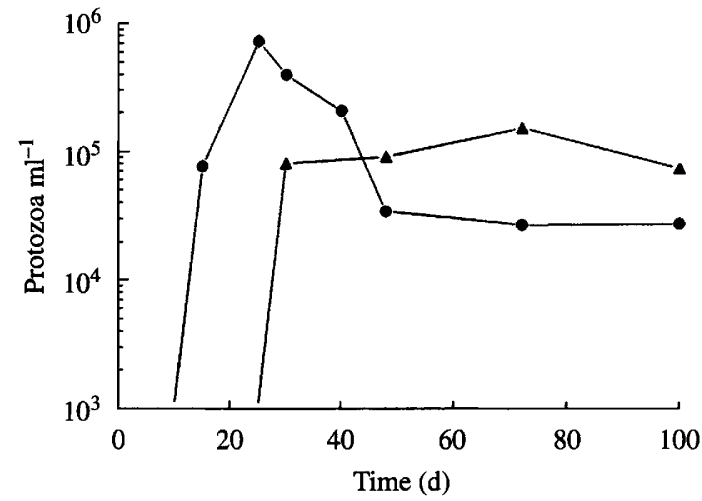

Fig. 1. Growth of ciliate PR3 (A) and flagellate PR4 (O) in medium containing coarse-grain $(61-200 \mu \mathrm{m})$ pyrite. Numbers of PR3 up to day 30 , and of PR4 up to day 15 , were $<10^{2} \mathrm{ml}^{-1}$. No protozoa were observed in medium containing fine-grain $(<61 \mu \mathrm{m})$ pyrite after day 1 of the experiment

hemispherical lobopodia; it was tentatively identified as a Vahlkampfia spp. (Page, 1976).

None of the protozoa was found to grow in liquid media containing fine grain $(<61 \mu \mathrm{m})$ pyrite or pyritic coal, although all grew when coarser grained (61$200 \mu \mathrm{m})$ minerals were used. Fig. 1 shows numbers of flagellate PR4 and ciliate PR3 in coarse-grain pyrite cultures. Appearance of the other three protozoan isolates in coarse-grain pyrite cultures was more sporadic, and no protozoa were observed in fine-grain mineral cultures beyond day one of the experiment. The distribution of bacterial species was found to be very similar in coarse- and fine-grain cultures, and, whilst pyrite oxidation was faster in fine-grain cultures, this is unlikely to have caused such rapid protozoan mortality. It appeared, therefore, that the lack of protozoan growth in $<61 \mu \mathrm{m}$ cultures was directly related to particle size of the minerals.

Numbers of iron-oxidizing bacteria and protozoa in pyritic coal (61-200 $\mu \mathrm{m}$ grain size) cultures are shown in Fig. 2(a-e). In this Figure, replicate cultures are shown separately as these occasionally displayed notable variations in protozoan numbers. After an initial decline, numbers of flagellate PR1 rose rapidly between days 10 and 30 , and remained at between $10^{5}$ and $10^{6} \mathrm{ml}^{-1}$ for the remainder of the experiment (Fig. 2a). The rise of flagellate numbers corresponded with a decline in numbers of iron-oxidizing bacteria in these cultures, and of differences becoming apparent between numbers of iron-oxidizers in protozoa-containing and control cultures. From day 40 to day 100 , numbers of unattached iron-oxidizing bacteria in cultures containing protozoa
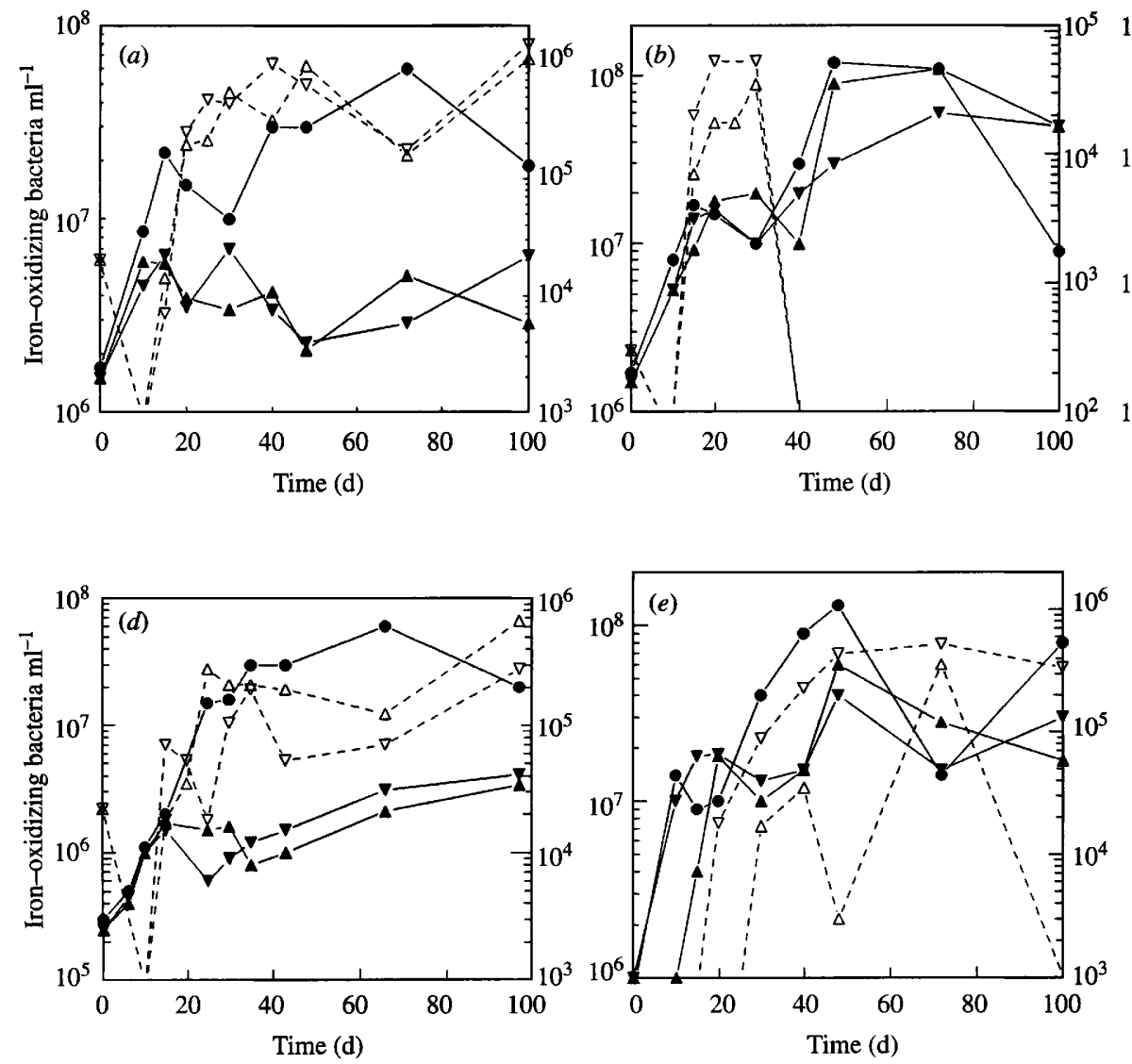

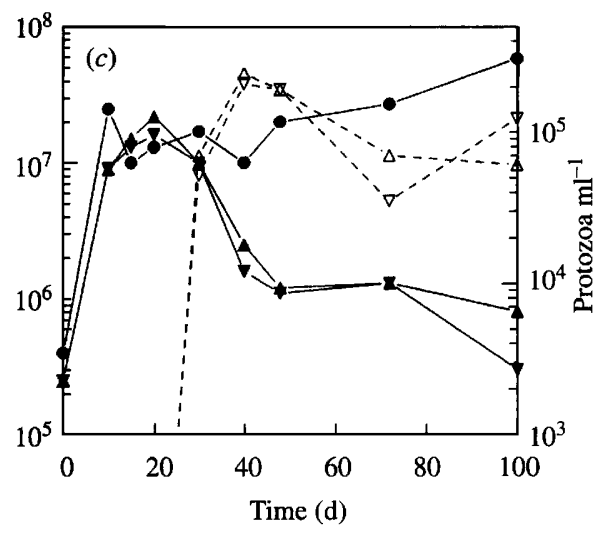

Fig. 2. Numbers of iron-oxidizing (continuous lines, filled symbols) and protozoa (broken lines, open symbols) in pyritic coal cultures inoculated with mixed microbial populations containing acidophilic protozoa, and corresponding protozoafree controls. (a) Flagellate PR1; (b) flagellate PR2; $(c)$ ciliate PR3; $(d)$ flagellate PR4; $(e)$ amoeba PR5. $\Delta, \boldsymbol{\nabla}$, Ironoxidizing bacteria (protozoa-containing cultures); , iron-oxidizing bacteria (protozoa-free controls); $\triangle, \nabla$, protozoa (no protozoa were present in control cultures). 
remained at about an order of magnitude below those in the control. The situation with cultures containing flagellate PR2 was very different, in that the protozoa increased in numbers between days 10 and 30 , but were not detected $\left(<100 \mathrm{ml}^{-1}\right)$ from day 40 to the end of the experiment. Iron-oxidizing bacterial populations were, as a consequence, far less affected than in other protozoan cultures (Fig. 2b). The ciliate protozoan (PR3) was not detected in pyritic coal cultures until day 30 of the experiment, but populations of about $10^{5} \mathrm{ml}^{-1}$ were maintained thereafter (Fig. $2 c$ ). The effect of this protozoan on iron-oxidizing bacterial populations was quite dramatic; by day 100 , numbers of unattached bacteria in ciliate-containing cultures were $<1 \%$ of those in the corresponding control culture. In contrast, flagellate PR4 attained high population densities much earlier (from day 15), resulting in about one order of magnitude lower numbers of iron-oxidizing bacteria than in the control culture (Fig. 2d). The trends in microbial populations found in cultures of isolate PR4 were similar to those of the other flagellate from Cae Coch mine, PR1 (Fig. 2a). However, numbers of both protozoa and iron-oxidizing bacteria were lower in cultures of isolate PR4, possibly indicating greater grazing efficiency. The two cultures containing the acidophilic amoeba, PR5, behaved quite differently in terms of protozoan populations, with one displaying a gradual increase in numbers from day 15 (maximum population $5 \times 10^{5} \mathrm{ml}^{-1}$ ), whilst numbers of amoebae in the replicate culture fluctuated widely (Fig. 2e). The reason for this was not apparent. Numbers of ironoxidizing bacteria were less affected by the presence of the amoeba than they were in cultures containing other protozoa cultures, with the exception of flagellate PR2.

Heterotrophic acidophilic bacteria were present in coal cultures throughout the $100 \mathrm{~d}$ incubation period, though numbers averaged about $1-10 \%$ of those of ironoxidizing bacteria. Again, the presence of protozoa produced diminished populations of heterotrophs, of between $20-60 \%$ of those in protozoa-free controls by the end of the experiment (data not shown).

Species distribution of iron-oxidizing bacteria in coal cultures changed over the $100 \mathrm{~d}$ incubation period. Due to the method by which the protozoa cultures were established, it would not be anticipated that the bacterial populations would be the same in them, though, as mentioned earlier, bacterial diversity in corresponding protozoa-containing and protozoa-free cultures was very similar at the start of the experiment. Examination of colonies of iron-oxidizing isolates revealed overall six different colony morphologies corresponding to $T$. ferrooxidans, and four corresponding to L. ferrooxidans. The percentages of total $L$. ferrooxidans isolates in coal leachates in the different cultures are shown in Fig. 3. In

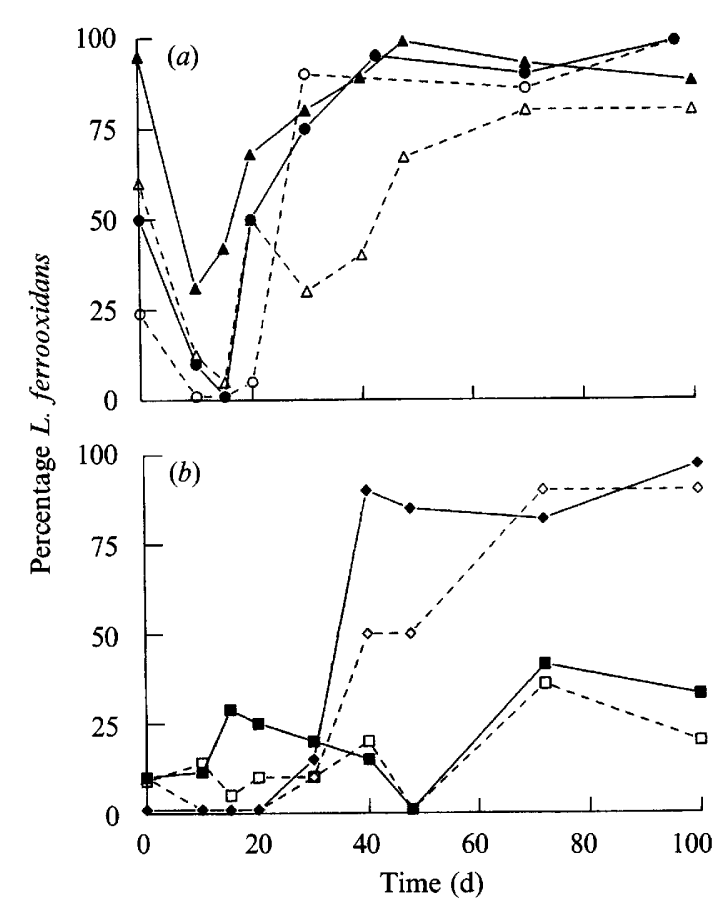

Fig. 3. L. ferroxidans as a percentage of total iron-oxidizing isolates in pyritic coal cultures containing protozoa (mean values; solid lines, filled symbols) and in corresponding protozoa-free controls (broken lines, open symbols). (a) Flagellates PR1 $(\boldsymbol{\Delta}, \triangle)$ and PR4 $(\bullet, \bigcirc) ;(b)$ ciliate PR3 $(\diamond, \diamond)$ and amoeba PR5 $(\boldsymbol{\square}, \square)$.

four cases (isolates PR1, PR2, PR3 and PR4) $L$. ferrooxidans became increasingly dominant as time progressed; this was the case in both protozoa-containing cultures and protozoa-free controls. In PR5 cultures (and the corresponding control) however, $T$. ferroxidans was consistently the dominant iron-oxidizer. The presence of protozoa PR1 and PR3 (and to a lesser extent PR4) resulted in L. ferrooxidans establishing as the dominant iron-oxidizing species earlier than in corresponding control cultures. No data are presented for PR2 cultures as the transience of this protozoan resulted in species distribution of iron-oxidizing bacteria being unaffected.

Rate of pyrite oxidation in the pyritic coal cultures, from increasing concentrations of soluble iron, are shown in Fig. 4. Again, data from PR2 cultures (and control) are not included, as no observable effects on pyrite oxidation were noted. The presence of the other two flagellate protozoa, PR1 and PR4, both produced net decreased rates in pyrite oxidation, though the effect was not as pronounced as that found with numbers of ironoxidizing bacteria, and corresponded to reductions in soluble iron concentrations of 15 and $24 \%$ (mean values), respectively, by day 100 . The control culture of PR5 also contained slightly less soluble iron than protozoa-containing cultures at day 100 . However, the ciliate protozoan PR3, although it had caused the most 


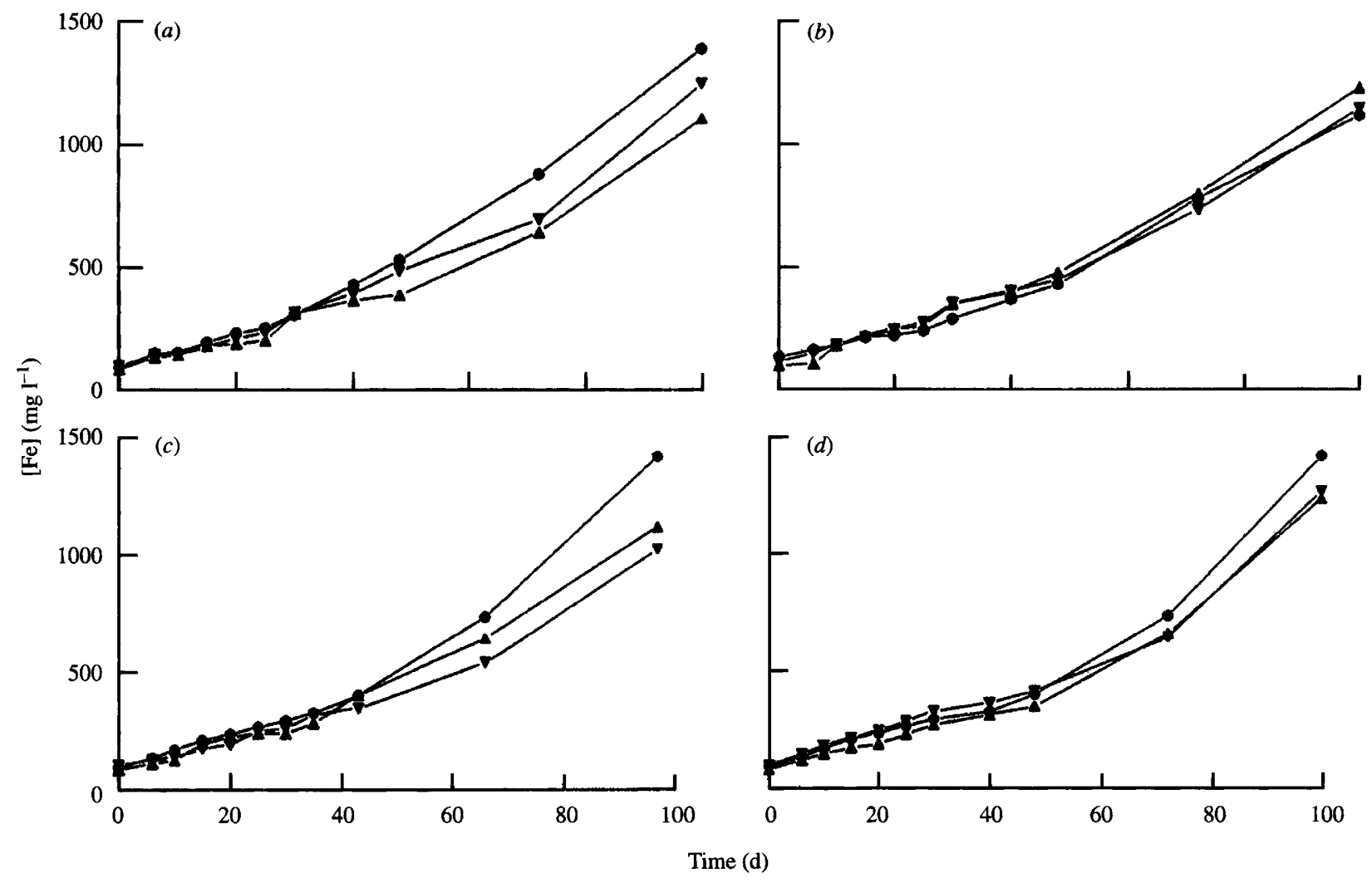

Fig. 4. Pyrite oxidation in coal cultures of acidophilic micro-organisms containing protozoa $(\boldsymbol{\Delta}, \boldsymbol{\nabla})$ and in corresponding protozoafree controls (@). (a) Flagellate PR1; (b) ciliate PR3; (c) flagellate PR4; (d) amoeba PR5.

dramatic reduction in numbers of unattached ironoxidizing bacteria, did not produce a decrease in pyrite oxidation; indeed, soluble iron concentrations were slightly higher in protozoa-containing than in protozoafree controls.

\section{Discussion}

It is apparent that protozoa capable of living in extremely acidic environments such as acid mine drainage and bioleachate liquors are taxonomically diverse. In the present study, representatives of three of the four traditional protozoan phyla (flagellates, ciliates and an amoeba) have been shown to live and multiply in defined acidic, metalliferous media in vitro. The fact that three of the five protozoa used in the current experiments were flagellates does not necessarily imply that this group contains more acidophilic species than other phyla. Other ciliates, quite distinct from PR3, have been observed in acid streamer growths, though these have not yet been cultured in the laboratory. Nevertheles, flagellates have frequently been found in a number of different extremely acidic sites by the present authors (unpublished data) and have been reported by other workers. McGinness \& Johnson (1992) showed that one of the flagellates used in the present study (PR1) was obligately acidophilic. Whether this is true of the other protozoa described in this paper has not yet been confirmed, though it has been shown that their tolerance of acidity is on a par with acidophilic bacteria. In the present study, flagellate PR4 and ciliate PR3 were active in oxidized pyrite cultures in which the $\mathrm{pH}$ had fallen to 1.6. The three flagellate isolates (PR1, PR2 and PR4), although quite probably belonging to the same genus (and possibly species) did differ in their behaviour in leaching experiments, with PR4 being the most active and PR2 the least. The reason for flagellate PR2 appearing to die out in pyrite and pyritic coal cultures is not known, but could indicate a lower tolerance to ferric iron. Similar behaviour has been noted in ferrous sulphate liquid media, though the organism does persist as inactive cysts under these conditions.

The apparent anomaly of acidophilic protozoa being eliminated from pyrite cultures, even though such cultures contained many bacteria and were not seemingly chemically hostile to the protozoa, appears to have been related to the particle size of minerals. It is possible that inadvertent ingestion of mineral (such as pyrite) particles of a size similar to that of bacteria results in the death of the protozoa. Mineral particles which are too large for 
ingestion do not cause protozoan mortality, though it may be anticipated that their continued oxidation by acidophilic bacteria would cause them to reduce in size and become increasingly lethal. However, the observation that acidophilic protozoa may be maintained over a protracted period by growing mixed cultures in a liquid medium containing coarse-grained pyritic coal has greatly facilitated laboratory handling of these microorganisms. Cultures grown for $10-20 \mathrm{~d}$ on pyritic coal and subsequently stored in the dark at room temperature, still contain active protozoa after a minimum of 3 months.

All of the protozoa grazed iron-oxidizing and heterotrophic acidophiles, though there was considerable variation in the extent to which they depleted bacterial populations. However, cell counts were of bacteria present in the liquid phase of cultures. Iron-oxidizing heterotrophic acidophiles are known to attach readily to solid substrata, such as pyrite crystals (Myerson \& Kline, 1983) and it is unknown to what extent, if any, grazing of bacteria attached to surfaces occurred. In addition, the affinities of the protozoa themselves for solid surfaces is unknown at present, and may differ significantly between isolates.

It is interesting that the smaller populations of unattached iron-oxidizing bacteria which resulted from protozoan grazing did not necessarily reduce the rate of pyrite dissolution, though this was the case with cultures containing flagellates PR1 and PR4. However, whilst numbers of unattached iron-oxidizing bacteria averaged about $10 \%$ of those in corresponding protozoa-free controls, soluble iron concentrations in PR1 and PR4 cultures were $75-85 \%$ of those in controls after $100 \mathrm{~d}$. The reduction in numbers of unattached iron-oxidizing bacteria resulting from grazing by ciliate PR3 was more pronounced, though here there was no corresponding decrease in pyrite solubilization. Two possible reasons for this are proposed: firstly, the numbers of bacteria attached to mineral surfaces were greater in PR3 cultures than in controls, and secondly, a more efficient pyriteoxidizing microflora existed in cultures containing PR3, as discussed below.

The presence of some of the protozoan isolates was noted to effect changes in species distribution of ironoxidizing bacteria, particularly during the earlier part (days 20-60) of the experiment. In earlier work, it was reported that $L$. ferrooxidans eventually became the most numerous iron-oxidizing bacterium in pyritic coal columns that had been inoculated with a mixed population of acidophiles (Johnson, 1991b). This was also found in four of the five cultures in the current experiments (i.e. all cultures except those containing isolate PR5 and the corresponding control; data from PR2 cultures are not shown). In cultures containing acidophilic protozoa isolates PR1 and PR3, L. ferrooxidans became the dominant iron-oxidizing acidophile at an earlier stage than in corresponding protozoa-free controls. This observation is in line with the finding of McGinness \& Johnson (1992) that acidophilic flagellate PR1 grazed $T$. ferroxidans in preference to $L$. ferrooxidans, and subsequently caused mixed cultures of ironoxidizers to become relatively enriched with $L$. ferrooxidans. Starter cultures of flagellates PR1 and PR4 contained higher $L$. ferrooxidans: $T$. ferrooxidans ratios than in the corresponding protozoa-free controls at the time of coal culture inoculation, even though all cultures had been grown for the same lengths of time. Again, this was considered to be due to selective grazing, though there was no subsequent evidence for changes in bacterial species distribution in coal cultures induced by isolate PR4. Whilst $L$. ferrooxidans became the dominant ironoxidizer in PR3 cultures and in the corresponding control, the colony and cellular morphologies of the dominant $L$. ferrooxidans strains in these cultures were quite different and distinct. In subsequent work (data not presented) the $L$. ferrooxidans isolate from the cultures which contained ciliate PR3 was found to oxidize pyrite at a faster rate than did the isolate from the PR3 control culture. It is therefore possible that selective grazing by PR3 resulted in selection of a strain of $L$. ferrooxidans which was a more rapid mineral oxidizer, mobilizing equivalent amounts of iron as the slower pyrite-oxidizing strain even when present in far lower numbers.

The potential significance of acidophilic protozoa in bioleaching operations is unclear at present. Whilst grazing by protozoa may both reduce numbers and change species and strain distribution of metalmobilizing bacteria, this does not necessarily result in lower leaching rates. There is a general concensus that protozoan grazing of bacteria in soil ecosystems results in net stimulation of bacterial activity and accelerates the rate of nutrient cycling (Sleigh, 1989). In situations where acidophilic protozoa have proliferated, it has generally been possible to eliminate or control them by adding copper sulphate, at a final $\left[\mathrm{Cu}^{2+}\right]$ of 1-5 mM. Flagellate PR1 was reported to be more sensitive than most acidophilic bacteria (particularly $T$. ferrooxidans) to copper (McGinness \& Johnson, 1992). However, adaptation of flagellate PR4 to $>5 \mathrm{mM}-\mathrm{Cu}^{2+}$ has been noted by the present authors (unpublished data) and addition of such concentrations of copper is undesirable as some strains of $L$. ferrooxidans may also be inhibited (Norris \& Ingledew, 1992). Relatively little is known at present about basic physiological and ecological aspects of acidophilic protozoa; future research will seek to elucidate, amongst other things, environmental constraints on their growth, and protozoan competition in mineral leaching cultures. 


\section{References}

Bos, P., Boogerd, F. C. \& Kuenen, J. G. (1992). Microbial desulfurization of coal. In New Concepts in Environmental Microbiology, pp. 375-403. Edited by R. Mitchell. New York: Wiley-Liss.

EHRLICH, H. L. (1963). Microorganisms in acid drainage from a copper mine. Journal of Bacteriology 86, 350-352.

HARRISON, A. P., JR (1984). The acidophilic Thiobacilli and other acidophilic bacteria that share their habitat. Annual Review of Microbiology 38, 265-292.

Johnson, D. B. (1991a). Diversity of microbial life in highly acidic, mesophilic environments. In Diversity of Environmental Biogeochemistry, pp. 225-238. Edited by J. Berthelin. Amsterdam: Elsevier.

Johnson, D. B. (1991 $b$ ). Biological desulfurization of coal using mixed populations of mesophilic and moderately thermophilic acidophilic bacteria. In Processing and Utilization of High-Sulfur Coals IV, pp. 567-580. Edited by P. R. Dugan, D. R. Quigley \& Y. A. Attia. Amsterdam: Elsevier.

Johnson, D. B. \& MCGinness, S. (1991). A highly efficient and universal solid medium for growing mesophilic and moderately thermophilic iron-oxidising, acidophilic bacteria. Journal of Microbiological Methods 13, 113-122.

Johnson, D. B., Kelso, W. I. \& Jenkins, D. A. (1979). Bacterial streamer growth in a disused pyrite mine. Environmental Pollution 18, $107-118$.
JosEPH, J. M. (1953). Microbiological study of acid mine waters: preliminary report. Ohio Journal of Science 53, 123-127.

LACKEY, J. B. (1938). The flora and fauna of surface water polluted by acid mine drainage. Public Health Report 53, 1499-1507.

MCGinness, S. \& JoHnson, D. B. (1992). Grazing of acidophilic bacteria by a flagellated protozoan. Microbial Ecology 23, 75-86.

Myerson, A. S. \& KLINE, P. (1983). The adsorption of Thiobacillus ferrooxidans on solid surfaces. Biotechnology and Bioengineering 25, $1669-1676$.

NoRRIS, P. R. (1990). Acidophilic bacteria and their activity in mineral sulfide oxidation. In Microbial Mineral Recovery, pp. 3-27. Edited by H. L. Ehrlich and C. L. Brierley. New York: McGraw-Hill.

NoRRIS, P. R. \& INGLEDEW, W. J. (1992). Acidophilic bacteria: adaptations and applications. In Molecular Biology and Biotechnology of Extremophiles, pp. 115-142. Edited by R. A. Herbert \& R. J. Sharp. Glasgow: Blackie.

PAGE, F. C. (1976). An Illustrated Key to Freshwater and Soil Amoebae. Ambleside, UK: Freshwater Biological Association.

PATterson, D. J. \& Hedley, S. (1992). Free-living Freshwater Protozoa: a Colour Guide. Aylesbury, UK: Wolfe Publishing.

SleIGH, M. (1989). Protozoa and Other Protists. London: Edward Arnold.

Walton, K. C. \& Johnson, D. B. (1992). Microbiological and chemical characteristics of an acid stream draining a disused copper mine. Environmental Pollution 76, 169-175. 